\title{
Internet of Things: An Implementation and Its Challenges in Malaysia
}

\author{
Ummi Wahida Badarudin ${ }^{\# 1}$, Wan Isni Sofiah Wan Din ${ }^{\# 2}$, Yuli Adam Prasetyo*, Zalili Musa ${ }^{\# 3}$ \\ and Shahreen Kasim ${ }^{+}$ \\ ${ }^{\#}$ Faculty of Computer Systems\& Software Engineering, University Malaysia Pahang, 26300 Gambang, Pahang, Malaysia \\ ${ }^{1}$ ummiwahida6@gmail.com; 2 sofiah@ump.edu.my; ${ }^{3}$ zalili@ump.edu.my
}

"School of Industrial Engineering, Telkom University, 40257 Bandung, West Java, Indonesia

${ }^{+}$Soft Computing and Data Mining Centre, Faculty of Computer Science and Information Technology, Universiti Tun Hussein Onn, Malaysia

\begin{abstract}
Internet becomes one of the technologies that is rapidly evolving and changing. It has become trending over the world. The Internet of Thing is a mechanism composed of devices, sensors, networks, cloud storage, and application. Each device able to communicate with another device over the Internet to share the information and accomplished some objectives. IoT is known as one of the new future technologies and were gaining attention from various fields over the countries. Malaysia is one of the countries in the planning stage to increase the development of IoT, which is equivalent to other countries with the emerging IoT applications development. However, it was not easy to develop IoT devices due to some issues and challenges in implementing IOT devices. This paper addresses the major concern and challenges in IOT and the solution how to overcome these issues. The future trends and applications of IoT were also briefly discussed in this paper for gaining more in-depth knowledge about the IOT technology.
\end{abstract}

Keywords: internet of things; IoT; implementation; challenges; Malaysia.

\section{INTRODUCTION}

To date, there are a lot of intelligent tools that available in the market and have directly linked to the Internet. The numbers of the devices keep increasing aligned with technologies changes. Smart devices are collectively part of the ecosystem that represents the digital revolution in the Internet of Things (IoT) [1]. IoT means, a connecting device that allows the communication occurs with the other devices and then the data will be captured and converted into valuable and meaningful information [1]-[5]. IoT primarily combined with technologies such as RFID, remote wireless communication, real-time localization, and sensor networks. Smart-phones, tablets, laptops are smart devices and technologies which are also considered as a component in the Internet of Things [6]. With IoT technologies, it can involve as many as connecting devices to facilitate the report in order to record the identity and location through wired or wireless communications [7]. Fig. 1 shows the descriptions about the Internet of Things [6]. According to respective figure, the Internet of Things is classified by anyone and anybody that attached with technologies, any services, and any business. It uses the multiple technologies to run their business - any path and any network to reach to any destinations as fast as possible, any place and anywhere to access or to use the technologies and also anything, any devices that available and have embedded with an intelligent system. All of these can be combined and produced one of the Internet of thing to reach and communicates with the people.

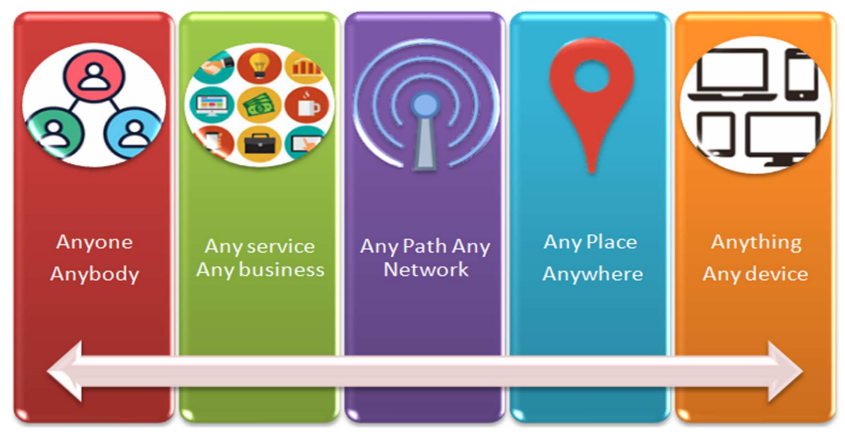

Fig. 1 Definitions The Internet of Things

The development of IOT steal attention and being recognized as innovative future technologies that were gaining interest from various fields over the countries [8]. Malaysia is not excluded from being one of the Southeast Asian countries that have the infrastructure required for IoT acceptance. Malaysian government launches IOT usage nationally by 2015. According to (National Internet of 
Things Strategic Roadmap, 2014) Malaysia has a strategic and structural background that applicable for the development of IOT and be a factor point to support and drive the IOT in the domestic market. Malaysia has been ranked as the leading digital economy among developing countries which ranks 4th for the Online Services Index at the United Nations E-Government Commission 2015.

A few factors are encouraging IoT development in Malaysia. The impact of the Internet of Things until the year 2025 is shown in Fig. 2. Mobile device penetration in Malaysia is beyond 150 percent and increase to 280 percent in 2025 due to the increasing number of mobile users nowadays. While 137 percent of Malaysians are Internet users and are expected that there will be increased exponentially to 190 percent in 2025 , relatively this is because active online behavior where beyond 59 percent of Malaysian Internet users download mobile apps compared to the Southeast Asian average at 67 percent [9]. Broadband penetration in Malaysia is almost 100 percent and expected increase to 170 percent in 2025 due to the increasing number of broadband subscriber among the user. According to One Device research, Mobile Malaysia, Ahead of the Pack, annually Malaysians spend an average of US\$2,000 on online purchases [10]. In another hand, close to one in every two Malaysians are active in social networking and lead to 75 percent social networking penetrations. Generally, with the increasing use of mobile devices and wider penetration of the Internet, Malaysia will become fertile ground for IOT implementation [11].

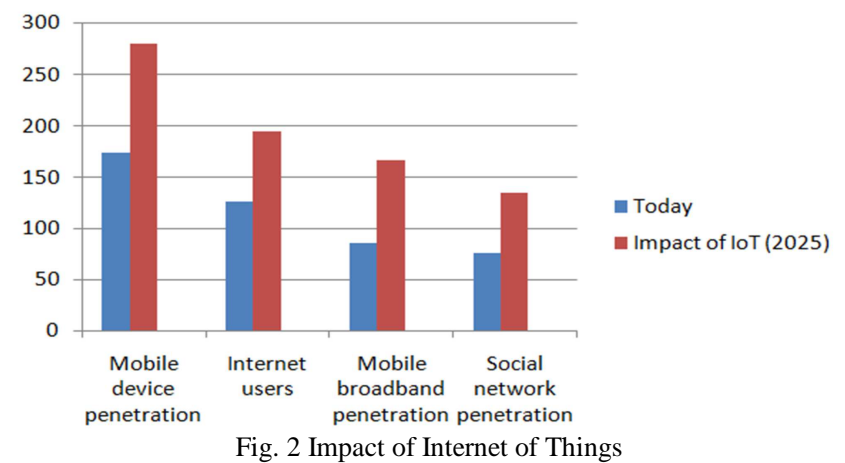

Kevin Ashton is the co-founder, and he was given the name of "Internet of Things." He is an Executive Director of MIT's Auto-ID laboratory in the 1999 [1], [2], [8], [9], [12][14], [15], [16]. The world has deployed about 5 billion "smart" connected things. Gartner, the world's well-known research and consultative company, predicts that 8.5 billion connecting devices had been used worldwide by 2017 . The percentage was increased by 32 percent from 2016 and expected will up to 20.9 billion by 2020 [17].

The Internet has gone through many different phases as accomplished by web evolution. The usages now are the more profound outcome for the society and business rather than the previous phase, which is more to individual ease. The World Wide Web and the Internet are two separate things, but both are related to each other. As well, the increased use of RFID, are providing opportunities to realize the Internet of Things. It also driven by market pulls, as the company is increasingly aware of the commercial benefits of applications that can be realized with the Internet Things technology [18]. The evolution of cell phone usage also a significant factor in the evolution of the Internet of Things [19] driven by the need to communicate anywhere and at any time.

In the 1990 s, the numbers of Internet connectivity were increased among business sectors and markets. However, due to slow network performance, it becomes limited used of the Internet devices. In the 2000s, Internet connectivity starting became attention for various user applications and were expected to be a part of the industry to access any information [20]. However, the connecting devices are still required human monitoring and interaction in order to maximize the applications. As shown in Fig. 3, the details information was stated regarding the evolution of the Internet in becoming the Internet of Things.

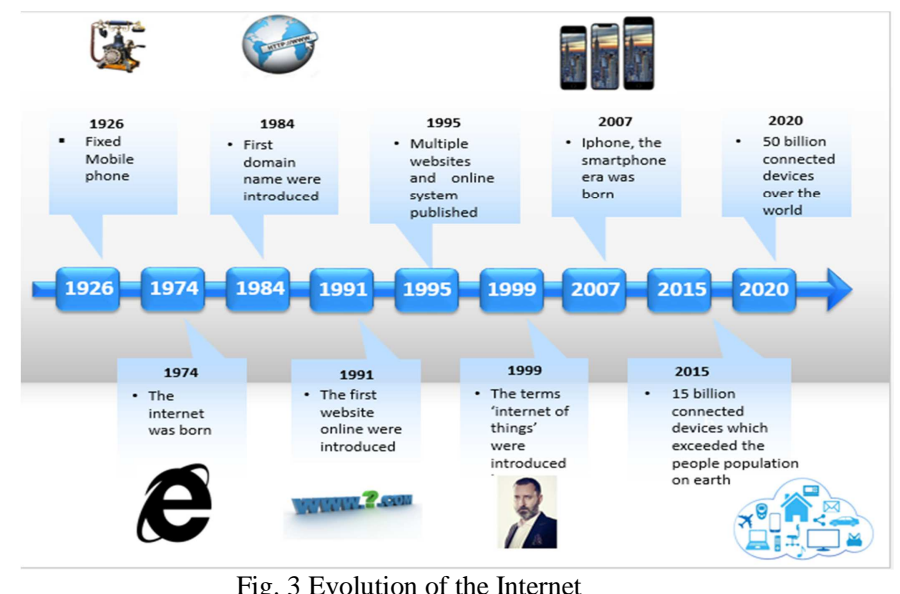

In recent years, many surveys were published to highlight the growth of research activities in the IOT technology development in each sector over the world. A few types of research have been made to relate and compare the previous works. The survey conducted in [21], the authors reviews the current study on IOT from the industrial point of view. Then, the research challenges and future trends associated with IOT technology were analyzed in the paper same as a vision in [14]. However, the paper was limited, which only concentrate on IoT applications in industrial, and highlights the challenges in the industrial sector without discussing the solution to IOT industry market to improve and overcome the encountered challenges.

The guideline and framework for product development and research that recognizes the context in IoT standards are studied [22]. A standardized review of current IoT invention exists in the marketplace and point out some of the important potential guidelines and trends to develop IoT [23]. However, the paper only discusses the IoT solution and neglect to address the issue and challenges in IoT implementation.

Besides that, the study of IoT entry in ICT market sector has classified into five categories, which are smart wearable that commonly used to monitor human health such as calories, heartbeats, and walking steps. The second category is smart home, which we can monitor, and control the house from the website or mobile phone. Thirdly is a smart city. The cities area can communicate with each other using the sensor devices, intelligent camera and so on. Fourthly, a 
smart environment where we can monitor the environment through the internet and lastly is smart enterprise [24]. The author briefly described and analyzed the useful and functionalities each application and provide the solution towards the respective sectors. However, the review paper only focuses on the IOT solution to the few IoT applications and neglects other marketplace products in other sectors such as IoT in logistic, healthcare, transportation and more.

Research in "Recent Trends in the Internet Article" [11] has been presented a summary of the different trends of IoT and describes the impact of IoT technology on our daily lives. It also discusses the importance of artificial intelligence and the significant usage of cloud computing in "Internet of Things." Next, it concludes with the needs of synchronization of the Internet, wireless sensors and distributed computing technology to enable successful IoT same as in [17].

This paper reviews the recent development and usage of IOT. Also, it will discuss the benefits of the Internet of Things from user perspectives and the current applications and implementation of IoT in a few sectors such as healthcare, transportation, agriculture, and academia. Then, the issues and challenges are discussed to describe threaten in IoT development in Malaysia, and lastly, this paper analyzes the future directions implementation of IoT in Malaysia. In order to achieve this paper's objective, comprehensive reviews were performed.

\section{MATERIAL AND METHOD}

Currently, there are plentiful of devices that link to the Internet such as robots, drones, and sensors. These kind of devices are mainly part of an ecosystem that represents today digital revolution, the IoT [25]. This ecosystem is composed of devices, sensors, networks, cloud storage, and applications, which are running altogether to help organizations to improve their strategic positioning proactively and effectively [26].

Architectures are necessary to represent the structure and organize the IoT that allows them to function effectively [27]. Fig. 4 shows the architecture of the Internet of Things [8].

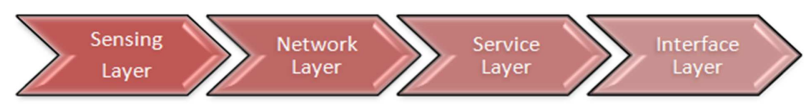

Fig. 4 Architecture of the Internet of Things [8]

\section{A. Sensing Layer (Hardware)}

Sensing layer can be defined as the combinations of the wireless sensor device, embedded systems, RFID readers and other sensors that are implemented in different forms. The hardware support identification and storage of the information, the collection of information from the sensor network, communication, and control of information processing are the key elements used in the sensor field.

\section{B. Networking and Communication}

The primary function of the network layer is to associate everything together and enabling them to distribute all the status including the information, evidence, material and sending it to the other connected things [28]. This layer is the first level of data management in IoT. The functions of the network layer include routing information, publishing, subscribing and also executes cross-platform to establishes the communication if needed. This network layer can compute and generate information from existing IT application [29]. Also, it must be able to dynamically change the network to detect and map out something over the network automatically. For designing network layer in IoT, it needs to be more focuses on the issues such as power consumption, network management, energy efficiency, quality of service (QoS), data retrieval, data processing and issues that need to be emphasized is the security and privacy on the network.

\section{Service Layer}

The service layer is responsible for device and information management. This layer also addresses issues such as data filtering, information discovery, integration services, service parts and controls access to the IoT technology.

\section{Interface Layer}

The interface layer is in charge of delivering multiple applications to different users and different sectors involving IOT technology. The applications are from different vertical industries such as manufacturing, logistics, healthcare, agriculture, automotive and many other sectors. With the enhancement of RFID technology, many growing applications will be under the term "Internet of Things".

Each of the IoT devices has their advantages that contribute to our life such as it can help individuals, businesses, enterprise, and communities nowadays. For individuals, this new concept may come in various fields of sectors including health, safety, business, and everyday activities [30]. Some of the IoT effects and how they affect our lifestyle is efficiency, cost saving, and better decisionmaking.

Efficiency in the Internet of Things is when it can facilitate communication between various types of devices or in the other word known as Machine-to-Machine (M2M) communication [31]. It is connected to physical devices, enabling communication with people and let them know about their condition and location. For example in the logistics sector, the used of trucks or vessels can communicate with other devices and people in order to handle the supplied data [32]. These combinations can optimum the income by reducing the cost of inefficiency in business thus making work more accessible and more effective.

IOT also function as a technology that able to reduce the cost on household needs. With this technology, it could take place the use of the workforce that is in charge of monitoring and managing the supplies. [33]. For instances, if the appliances can communicate with each other, they can cooperate efficiently and effectively without the need for the workforce. Additionally, IoT can help people with their daily plans. Devices that communicate with each other will collect the data, share, and then convert the data into useful information of the current system. The application could be more efficient and also can save energy of the devices [34]. 
Another advantage of IoT to the human is, it capable of helping people in making decisions. Connecting devices can make decisions wisely without human guidance and automatically can reduce energy. The huge capacities of data retrieved from any types of sensors devices can be added to the storage of big data to inform strategic and operational decision making. If the device analyzes larger trends from empirical data [34], then smarter, the decision can be made. Development of IoT technology in Malaysia promises numerous benefits to the public such as increasing economic efficiency and productivity through the automation and prescription of activities. Then, by developing IoT also able to reduce risks of the environment through real-time sensing and providing information [35]. Next, Internet of Things is able for facilitating the Government in developing better infrastructure in utility planning monitoring and management through data augmentation. Last but not least, IOT will be able to enhance knowledge by enabling people to understand and monitor previously inaccessible domains through the availability and visibility of information [36] in every aspect over the world.

\section{RESULTS AND DISCUSSION}

Across the world, the majority of countries are envisioning smart city initiatives that focus on energy, water, transportation, buildings and government [37]. Eighty-four percent of the initiatives are led by five countries including the United States, European countries, Japan, China, and Korea. Other countries including India, Australia, South Africa, Canada, and Singapore are also now moving towards building digital and connected infrastructures [24]. By the end of this decade, billions of things will become smarter and smarter and will significantly improve the way of life.

\section{A. Implementations Internet of Things in Malaysia}

Malaysia is not excluded from being one of the Southeast Asian countries that have the infrastructure required for IoT acceptance. The Malaysian government even launches IoT usage nationally by 2015. However, there are some challenges to IOT for a massive departure in Malaysia. For Malaysia, there are also strategies related activities and initiatives to the development of IoT devices connected to the other countries that emerged in the development of IoT. With the intelligent of IOT, everyone and everything can be directly connected at all times, receive and process information in real-time. The result will be a new way of making decisions [38] and supported by the availability of meaningful information.

1) Vision and Mission: The vision and mission are formulated to afford a clear strategy throughout the implementation and development of IoT in Malaysia. It serves as a guide and declaration of purpose for Malaysia to work in a synergistic manner that will lead to be the Premier Regional IOT Development Hub and make IOT a new source of growth. Automatically, this technology can provide job opportunities and be the catalyst and energizer for all stakeholders. According to National Roadmap 2014, the vision of IoT development in Malaysia is going to be the Premier Regional IOT Development Hub. The mission is to create a national ecosystem. It is to establish the industrialization of IOT where technology proliferation being part of the new source in economic growth. The mission consists of the following elements:

- Develop and maintain a competitive IoT industry in the world with capabilities, innovations, and values that exceed regional competitors.

- Enables strategic cooperation and maintaining productive partnerships.

- Facilitate the industry in developing and deploying IoT technology that is cost-effective.

- Attract, build and maintain leading skills in IOT technology and improve small and medium enterprises to the next level in IOT space.

- Strengthen the industry's ability to maintain robust economic performance.

All the elements need to be refined so that, the implementation could be effective manners without wastage of resources. Several sectors have been slowly developed and implemented Internet of Things. Logistics, healthcare, automotive and agriculture are the example of sectors that grow the development of connected device in intend to build efficient and robust work [39]. The objective to encourage the development of IOT in Malaysia is to provide a better quality of life by utilizing ICT applications. Healthcare, transportation, agriculture, and academia are the target sectors to implement IoT.

2) Healthcare: There is a large number of IoT applications adopt in the healthcare sector. In healthy and wellness, they use this application for a better quality of life and also contribute to a healthier lifestyle [40]. For example, each patient will have a smart medical sensor to monitor the body parameter such as body temperature, blood pressure, breathing and more. There are also other sensors such as wearable sensors. This sensor can be categories that can gather data by monitoring patient activity through their lifestyle and their environment [41]. While Malaysia goals in the healthcare sector are to promote healthy living and wellness assisted by digital lifestyle services through enhanced health service availability everywhere and anytime.

3) Transportation: At every transport layer, IOT provides better two-way communication, control, and data distribution. These applications include personal vehicles such as the car, commercial vehicles like trains, UAVs and other equipment [42]. IoT technologies cover the whole system of transport elements start with traffic control, parking, fuel consumption, and more. Malaysia's objective in the transportation sector is one of the top five in Asia Pacific container and container trails. Also, Malaysia also seeks the chance to enhance trade facilities and enhance Malaysia's competitive advantage regarding supply chain management practices. Suggested applications include E-parking, taxi reservations, bus transportation information, and finally yet importantly travel and train information tips with real-time information for easy traveling.

4) Agriculture: While in agriculture, IoT technologies are required for managing agricultural and animals farming. IoT also used for monitoring and tracking their movement regularly. Example of IoT application is real-time tracking of animals, especially during the diseases that can affect the 
animals. Therefore, the existence of system identification, the diseases from the animals can be controlled and prevented [43]. Malaysia's target in the agriculture sector is to an emphasis on food ability by strengthening Malaysia's reputation for food quality and as a Halal hub.

5) Academic: In academic sectors, Malaysia plans to develop and distribute new techniques, reference data, and materials, testing methods, other infrastructure, and technology services required by the IOT industry of Malaysia to keep going its competitiveness. Today, Malaysia is headed and realized a new learning method that suggests the use of open learning called Massive Open Online Course (MOOC). This learning method allows all of the community access the open learning source anytime and anywhere besides can share knowledge within each other. The objective of Malaysia in the academic sector is to create a conducive learning environment and to foster lifelong learning.

IOT is aggressively developing over the world. The real value of IoT is achieved through the integration of things and knowledge in decision-making will be incorporated into the business the personal environment and our society. Despite acknowledging the high potentials of IOT, numerous challenges need to be issued. Every country that had starts IOT deployment facing the issues and challenges to maintain the operability of IOT. Malaysia also disguises the same issues to realize IOT development. A few main issues were briefly described. The main challenge for the construction of IoT technology in Malaysia is the integration of various network technologies in public IP networks to ensure scalable and reliable network communication [44]. With the increase of IoT technology deployment, each sector required to consider their networking elements to ensure the efficient data transmission between the wired and wireless networks. IOT relies on connectivity and reliability to communicate for Future Internet architecture [45].

\section{B. Security and Privacy in Data Transaction.}

Security is becoming big issues that need to consider in the deployment of IoT technology [46]-[53]. For companies that have started on an IOT Strategy Plan are facing concerns over security and privacy methods and management of the data [51]-[57]. IoT needs to ensure privacy, security, authority, integrity and user confidentiality of the data information. All of the IOT technologies need to deal with the authorization, authentication and access control. Also, guidelines and policies in defining the ownership of information, privacy, and security must be implemented to gain market confidence and safeguard national dignity [61]-[63].

\section{Implementation Difficulties and Ease of Use Issues}

IOT will grow from time to time with the new usage, new requirements, and new technologies. IoT is growing in many different sectors, with the development of significant technologies, it competing for each other to become the leader in the respective field [64]. This will effect technical hitches and requires additional hardware and software for connecting the devices. There is also a gap in building a product that can work well with other devices, and standard setting.
Therefore, ensure interoperability and connectivity of heterogeneous technologies is very important for the successful launch IOT in Malaysia. Through this mechanism, a collaborative platform to develop IoT solutions can be formulated based on the improvement of life regarding safety, comfort, and quality in general [65]. This will be one focus for Malaysia as the Premier Regional IOT Development Hub.

\section{Adoption and Adaption}

Due to the growing development of IOT, IOT will be a platform for inclusiveness which "Internet for Everyone" where everyone in the community can participate equally and contribute to social and economic IOT development. However, in rural communities, there might be phobia to technology and slow usage either the mobile phone or the internet usage. It was about the readiness of the community to accept the Internet of Things in their life [63], [64]. They also need to adapt to how these technologies will affect their lives.

\section{E. Governance Policies}

Therefore, the role of the Government in the development of the IoT industry is significant and meaningful. The government should give local players the opportunity to participate actively in IoT and use technology to revolutionize their business and automatically accelerate the distribution of IoT in Malaysia. Among the initiatives that can be taken is to provide funds to inculcate and incentivize them to remain eager to realize the country's goals and become one of the developing countries with IoT technology development [69].

\section{F. High Cost of IOT Deployments}

Implementing the IOT can be expensive. Starting with all of the hardware required software and cost for network infrastructure. It does not include the cost after developing devices, cost for implementation and maintenance that are needed to ensure the interoperability of the devices [70]. Malaysia relies on the access planning of IoT devices with a centralized cloud-based business model [71]. This method results in many years of expenditures or maybe even decades without profit.

All the challenges in the implementation of Internet of Things need to take the severe action to realize Malaysia's objective to be a developing IOT technology to equivalent with other countries.

To capitalize on the huge potential of IoT, Malaysia needs to embed success factors and a proper execution plan. The following list briefly highlights recommendations to realize IOT in Malaysia:

1) Financial and Incentives: Cost is major obstacle to small and medium-sized businesses in realizing IOT usage in field ICT [34].Therefore, it is recommended that the Government provide a financial or special fund to motivate and utilize IoT for future development and achievements. Industrial can compete with each other for providing good services towards the IoT.

2) Awareness Campaign and Programs: Awareness the existence of IOT is superficial. Now, entrepreneurs are not convinced of the necessity of the use of such these 
technologies for their enterprises. Therefore, the Government should initiate and support awareness campaigns and strategic development programs to enhance the capacity of IOT technologies. Awareness and support campaign also need to hold for the rural community in order for them can adapt to the acceptance development of IOT technology. In contrast, for rural communities, IOT technologies have the potential to generate new income. With the connectivity and availability of information, this will raise interest from visitors, residents, workers, and entrepreneurs to previously unknown areas and renew the lives of existing businesses by expanding markets. Connections within communities also can be established. Communities can work together in local opportunities to form new skills and markets. Automatically, IoT can generate a more active and competitive economy.

3) Innovative Applications and Development: Applications and services decline eighty percent of IOT driven market opportunities. Thereby, contributing to productive business opportunities for service-based entrepreneurs are essential to developing applications and services for their respective target markets such as health monitoring, logistics management, fleet management, and monitoring management. While in learning institutions, the campus also can organize some technology innovation events or competition for IOT-based technology to promote the students the importance of IOT in industry.

4) Enhance Collaboration: Linkages and collaborations across the innovation ecosystem between industry players, the academic and research institutions must be approached systematically. These approaches are for developing innovative technology and serve the needs of entrepreneurs effectively thereby granting early access to investors on new promising ideas. Thus, a three-party combination helps enable idea generation and development, capability enhancement, access to shared infrastructure, and ultimately commercialization of the IOT technology.

5) Talent and Workers: There is also a need to prepare the workforce for the future in IOT. Educational institutions need to be equipped with relevant syllabus and facilities for the growth of IoT professionals. This institution must be able to generate producers and suppliers, not only consumers of technology. While learning institutions need to provide a strong foundation for Science and Engineering students and enhance it further in order to produce solid IOT professionals. Moving forward, the education industry could give rise to potential talents able to build better solutions for the future. Also, guidelines and policies in defining the ownership of information, privacy and security must be implemented to gain market confidence towards the deployment IOT in Malaysia.

\section{CONCLUSIONS}

The major contributions that have been covered are; the review of the current trends in IoT implementation, the benefits of the Internet of Things which describe the importance of IoT to people as IoT user. Next is the application of IOT in a few sectors such as healthcare, transportation, agriculture, and academia. Then, the issues and challenges were discussed to describe threaten in IoT development in Malaysia, and lastly, the future directions implementation of IOT in Malaysia were analyzed. Malaysia needs to implement a cohesive national innovation strategy to gain IOT benefits and as a boost to achieve the aspiration of Vision 2020 high-income economy. Instead of creating new projects, Malaysia needs to identify selected key sectors that will gain membership domains in the IoT and provide ongoing competitiveness over time. To be critical, the success of Malaysia's innovation strategy relies on excellent execution by a combination of talent, infrastructure, and the appropriate source. Here, the entity that is knowledgeable and influential market must lead the effort to streamline the country's innovation agenda and improve the current gaps in the landscape of the innovation ecosystem in Malaysia. With that, Malaysia can stand on par with the outside world of IOT's rapidly developing and worldwide development with current achievements.

\section{REFERENCES}

[1] I. Paper, "The Web of Things : A Survey," vol. 6, no. 6, pp. 424-438, 2011.

[2] J. Mineraud, O. Mazhelis, X. Su, and S. Tarkoma, "A gap analysis of Internet-of-Things platforms," Comput. Commun., vol. 89-90, pp. 516, 2016.

[3] Y. Zhang and X. Wu, "Access Control in the Internet of Things: A Survey."

[4] D. Singh and A. J. Jara, "A survey of Internet-of-Things: Future Vision, Architecture, Challenges and Services," pp. 287-292, 2014.

[5] B. Torğul, L. Şağbanşua, and F. Balo, "Internet of Things : A Survey Internet of Things : A Survey," no. March 2017.

[6] A. J. Jara, L. Ladid, and A. Skarmeta, "The Internet of Everything through IPv6: An Analysis of Challenges, Solutions, and Opportunities," J. Wirel. Mob. Networks, Ubiquitous Comput. Dependable Appl., vol. 4, no. 3, pp. 97-118, 2013.

[7] A. Kamilaris and A. Pitsillides, "Mobile phone computing and the Internet of Things: a survey," IEEE Internet Things (on print), vol. 3, no. 6, pp. 1-13, 2016.

[8] A. Al-fuqaha, M. Guizani, M. Mohammadi, M. Aledhari, and M. Ayyash, "Internet of Things: A Survey on Enabling Technologies, Protocols and Applications Internet of Things: A Survey on Enabling Technologies, Protocols, and Applications," vol. 17, no. January, pp. 2347-2376, 2015.

[9] R. H. Weber and E. Studer, "Cybersecurity in the Internet of Things: Legal aspects," Comput. Law Secure. Rev., vol. 32, no. 5, pp. 715$728,2016$.

[10] T. Saarikko, U. H. Westergren, and T. Blomquist, "The Internet of Things: Are you ready for what's coming?," Bus. Horiz., vol. 60, no. 5, pp. 667-676, 2017.

[11] S. Maharjan, "RFID and IOT: An overview," Simula Res. Lab. Univ. Oslo, 2010

[12] S. Bandyopadhyay, M. Sengupta, S. Maiti, and S. Dutta, "Role of Middleware For Internet of Things : A Study," vol. 2, no. 3, pp. 94105, 2011.

[13] C. Perera, S. Member, A. Zaslavsky, P. Christen, and D. Georgakopoulos, "Context-Aware Computing for The Internet of Things : A Survey," vol. 16, no. 1, pp. 414-454, 2014.

[14] H. N. Saha, A. Mandal, and A. Sinha, "Recent trends in the Internet of Things," 2017 IEEE 7th Annu. Comput. Commun. Work. Conf., pp. 1-4, 2017.

[15] D. Miorandi, S. Sicari, F. De Pellegrini, and I. Chlamtac, "Internet of things: Vision, applications and research challenges," Ad Hoc Networks, vol. 10, no. 7, pp. 1497-1516, 2012.

[16] L. Hou et al., "Internet of Things Cloud: Architecture and Implementation," IEEE Commun. Mag., vol. 54, no. 12, pp. 32-39, 2016.

[17] J. Gubbi, R. Buyya, S. Marusic, and M. Palaniswami, "Internet of Things ( IoT ): A vision, architectural elements, and future directions," Futur. Gener. Comput. Syst., vol. 29, no. 7, pp. 1645-1660, 2013.

[18] S. Sicari, A. Rizzardi, L. A. Grieco, and A. Coen-porcini, "Security, privacy and trust in the Internet of Things : The road ahead," Comput. Networks, vol. 76, pp. 146-164, 2015. 
[19] C. Tsai, C. Lai, M. Chiang, and L. T. Yang, "Data Mining for Internet of Things : A Survey," vol. 16, no. 1, pp. 77-97, 2014.

[20] L. Atzori, A. Iera, and G. Morabito, "The Internet of Things: A survey," Comput. Networks, vol. 54, no. 15, pp. 2787-2805, 2010.

[21] L. Da Xu, W. He, and $\mathrm{S}$. $\mathrm{Li}$, "Internet of things in industries: A survey," IEEE Trans. Ind. Informatics, vol. 10, no. 4, pp. 2233-2243, 2014.

[22] C. Perera, C. H. L. Member, S. Jayawardena, and M. Chen, "Context-aware Computing in the Internet of Things: A Survey on Internet of Things From Industrial Market Perspective,” vol. 2, 2015.

[23] D. Bandyopadhyay and J. Sen, "Internet of Things : Applications and Challenges in Technology and Standardization," pp. 49-69, 2011.

[24] C. Perera, C. H. Liu, and S. Jayawardena, "The Emerging Internet of Things Marketplace from an Industrial Perspective: A Survey," IEEE Trans. Emerg. Top. Comput., vol. 3, no. 4, pp. 585-598, 2015.

[25] C. M. Medaglia and A. Serbanati, "An Overview of Privacy and Security Issues in the Internet of Things," pp. 389-395, 2010.

[26] A. Botta, W. De Donato, V. Persico, and A. Pescapé, "Integration of Cloud computing and Internet of Things: A survey," Futur. Gener. Comput. Syst., vol. 56, pp. 684-700, 2016

[27] M. Díaz, C. Martín, and B. Rubio, "Journal of Network and Computer Applications State-of-the-art, challenges , and open issues in the integration of Internet of things and cloud computing," J. Netw. Comput. Appl., vol. 67, pp. 99-117, 2016.

[28] K. Gusmeroli, S., Haller, S., Harrison, M., Kalaboukas, K. Tomasella, M., Vermesan, O., \& Wouters, Vision and challenges for realizing the internet of things, vol. 1, no. April. 2009.

[29] A. M. Ortiz, D. Hussein, S. Park, S. N. Han, and N. Crespi, "The Cluster Between Internet of Things and Social Networks: Review and Research Challenges," IEEE Internet Things J., vol. 1, no. 3, pp. 206-215, 2014

[30] R. Khan, S. U. Khan, R. Zaheer, and S. Khan, "Future internet: The internet of things architecture, possible applications and key challenges," Proc. - 10th Int. Conf. Front. Inf. Technol. FIT 2012, no. December, pp. 257-260, 2012.

[31] S. Engineering, S. Arabia, and D. Campus, "A Review on Internet of Things ( loT ), Internet of Everything ( $\mathrm{IoE}$ ) and Internet ofNano Things ( IoNT )," Internet Technol. Appl., pp. 219-224, 2015.

[32] S. Bhardwaj and A. Kole, "Review and study of internet of things: It's the future," 2016 Int. Conf. Intell. Control Power Instrum., pp. $47-50,2016$

[33] D. Uckelmann, M. Harrison, and F. Michahelles, "Architecting the Internet of Things," pp. 1-24, 2011.

[34] I. Lee and K. Lee, "The Internet of Things (IoT): Applications, investments, and challenges for enterprises," Bus. Horiz., vol. 58, no. 4, pp. 431-440, 2015

[35] C. Falkenreck and R. Wagner, "The Internet of Things - Chance and challenge in industrial business relationships," Ind. Mark. Manag. vol. 66, no. August, pp. 181-195, 2017.

[36] R. Girau and L. Atzori, "Internet of Things. IoT Infrastructures," vol. 170, no. January 2016, 2016.

[37] J. Yu, H. C. Bang, H. Lee, and Y. S. Lee, "Adaptive Internet of Things and Web of Things convergence platform for Internet of reality services," J. Supercomput., vol. 72, no. 1, pp. 84-102, 2016

[38] M. A. Chaqfeh and N. Mohamed, "Challenges in middleware solutions for the internet of things," Proc. 2012 Int. Conf. Collab. Technol. Syst. CTS 2012, pp. 21-26, 2012

[39] V. M. Tayur, "Application Layer of Internet of Things," no. Icimia, pp. 322-326, 2017.

[40] Y. Ma, Y. Wang, J. Yang, Y. Miao, and W. Li, "Big Health Application System based on Health Internet of Things and Big Data," IEEE Access, vol. 5, pp. 7885-7897, 2017.

[41] N. Asghar, Mohsen Hallaj and Negi, Atul and Mohammadzadeh, "Principle Application and Vision in Internet of Things ( IoT )," Int. Conf. Comput. Commun. Autom., pp. 427-431, 2015.

[42] H. F. Chong and D. W. K. Ng, "Development of IoT device for traffic management system," Proc. - 14th IEEE Student Conf. Res. Dev. Adv. Technol. Humanity. SCOReD 2016, 2017.

[43] R. Nukala, K. Panduru, A. Shields, D. Riordan, P. Doody, and J. Walsh, "Internet of Things: A review from \#x2018; Farm to Fork \#x2019;" 2016 27th Irish Signals Syst. Conf., pp. 1-6, 2016.

[44] T. Guarda et al., "Internet of Things challenges," 2017 12th Iber. Conf. Inf. Syst. Technol., pp. 1-4, 2017.

[45] H. Rahman and R. Rahmani, "Enabling distributed intelligence assisted Future Internet of Things Controller (FITC)," Appl. Comput. Informatics, pp. 1-15, 2017
[46] S. Elbounani, M. A. El Kiram, and O. Achbarou, "Introduction to the Internet of Things Security," 11th Int. Conf. Inf. Assur. Secur., no. March, pp. 1-29, 2015.

[47] M. Abomhara, "Security and Privacy in the Internet of Things: Current Status and Open Issues," Priv. Secure. Mob. Syst. (PRISMS), 2014 Int. Conf., pp. 1-8, 2014

[48] G. Gan, Z. Lu, and J. Jiang, "Internet of Things Security Analysis," 2011 Int. Conf. Internet Technol. Appl., pp. 1-4, 2011.

[49] T. Borgohain, U. Kumar, and S. Sanyal, "Survey of Security and Privacy Issues of the Internet of Things," arXiv Prepr. arXiv1501.02211, p. 7, 2015.

[50] M. M. Hossain, M. Fotouhi, and R. Hasan, "Towards an Analysis of Security Issues, Challenges, and Open Problems in the Internet of Things," 2015 IEEE World Congr. Serv., pp. 21-28, 2015.

[51] Q. Jing, A. V Vasilakos, J. Wan, J. Lu, and D. Qiu, "Security of the Internet of Things: perspectives and challenges," Wirel. Networks, vol. 20, no. 8, pp. 2481-2501, 2014

[52] S. A. Kumar, T. Vealey, and H. Srivastava, "Security in the internet of things: Challenges, solutions, and future directions," Proc. Annu. Hawaii Int. Conf. Syst. Sci., vol. 2016-March, pp. 5772-5781, 2016.

[53] S. Mansfield-Devine, "Securing the Internet of Things," Comput. Fraud Secur., vol. 2016, no. 4, pp. 15-20, 2016.

[54] Z. Yan, P. Zhang, and A. V. Vasilakos, "A survey on trust management for the Internet of Things," J. Netw. Comput. Appl., vol. 42, pp. 120-134, 2014.

[55] R. H. Weber, "Internet of Things - New security and privacy challenges," Comput. Law Secure. Rev., vol. 26, no. 1, pp. 23-30, 2010

[56] A. Ukil, J. Sen, and S. Koilakonda, "Embedded security for the internet of things," Proc. - 2011 2nd Natl. Conf. Emerg. Trends Appl. Comput. Sci. NCETACS-2011, pp. 50-55, 2011.

[57] C. Tankard, "The security issues of the Internet of Things," Comput. Fraud Secur., vol. 2015, no. 9, pp. 11-14, 2015.

[58] L. M. R. Tarouco et al., "Internet of Things in healthcare: Interoperability and security issues," IEEE Int. Conf. Commun., pp. 6121-6125, 2012

[59] H. Suo, J. Wan, C. Zou, and J. Liu, "Security in the internet of things: A review," Proc. - 2012 Int. Conf. Comput. Sci. Electron. Eng. ICCSEE 2012, vol. 3, pp. 648-651, 2012.

[60] L. Singh Sayana and B. K. Joshi, "Security Issues in the Internet of Things," Glob. Challenges - Role Sci. Technol. Imparting their Solut. TIT\&S Bhiwani, no. October 2016.

[61] C. Tankard, "The security issues of the Internet of Things," Comput. Fraud Secur., vol. 2015, no. 9, pp. 11-14, 2015.

[62] C. Liu, "Securing networks in the internet of things era," Comput. Fraud Secur., vol. 2015, no. 4, pp. 13-16, 2015.

[63] M. Abomhara and G. M. Kien, "Cyber Security and the Internet of Things: Vulnerabilities, Threats, Intruders, and Attacks," J. Cyber Secur. Mobil., vol. 4, no. 1, pp. 65-88, 2015.

[64] Q. Wang et al., "Multimedia IoT systems and applications," GIoTS 2017 - Glob. Internet Things Summit, Proc., no. 2, 2017.

[65] P. Suresh, J. V. Daniel, V. Parthasarathy, and R. H. Aswathy, "A state of the art review on the Internet of Things (IoT) history, technology and fields of deployment," 2014 Int. Conf. Sci. Eng. Manag. Res., pp. 1-8, 2014.

[66] F. J. Riggins and S. F. Wamba, "Research directions on the adoption, usage, and impact of the internet of things through the use of big data analytics," Proc. Annu. Hawaii Int. Conf. Syst. Sci., vol. 2015March, pp. 1531-1540, 2015.

[67] K. Patil, "Retail adoption of Internet of Things: Applying TAM model," Int. Conf. Comput. Anal. Secure. Trends, CAST 2016, pp. 404-409, 2017

[68] A. Luqman and J.-P. Van Belle, "Analysis of human factors to the adoption of Internet of Things-based services in informal settlements in Cape Town," 2017 1st Int. Conf. Next Gener. Comput. Appl. NextComp 2017, 2017

[69] S. Lanka, S. Ehsan, and A. Ehsan, "A review of research on emerging technologies of the Internet of Things and augmented reality,” 2017 Int. Conf. I-SMAC (IoT Soc. Mobile, Anal. Cloud), pp. 770-774, 2017.

[70] H. N. Saha, N. Saha, R. Ghosh, and S. Roychoudhury, "Recent trends in implementation of Internet of Things-A review," Inf Technol. Electron. Mob. Commun. Conf. (IEMCON), 2016 IEEE 7th Annu., pp. 1-6, 2016.

[71] K. B. Ooi, V. H. Lee, G. W. H. Tan, T. S. Hew, and J. J. Hew, "Cloud computing in manufacturing: The next industrial revolution in Malaysia?," Expert Syst. Appl., vol. 93, pp. 376-394, 2018. 